JOALL (JOURNAL (DF APPIIEI) LINGUIS'IICS ANI) LI'TIRA'TURE)

Vol. 4 No. 2, 2019

ISSN (print): 2502-7816; ISSN (online): 2503-524X

Available online at https:/ / ejournal.unib.ac.id/index.php/joall/index doi: http:// dx.doi.org/10.33369/joall.v4i2.7797

\title{
STRUCTURAL METAPHOR OF LOVE IN ENGLISH SONGS IN THE LATE 20TH CENTURY FROM STYLISTIC AND COGNITIVE PERSPECTIVES
}

\author{
Nguyen Thi Hong Thu'
}

\author{
Hanoi Law University
}

\section{Corresponding email: thu.nth@hlu.edu.vn}

\begin{abstract}
:
Metaphor is a powerful linguistic device for musicians to write love songs. Through love songs, metaphor is understood and studied more interestingly and effectively. The paper identified distinctive linguistic features of metaphors as well as interpreted the metaphorical images of love in the songs. The data for analysis are the samples randomly taken from English love songs in the late 20th century. There are 68 songs used with 80 verses included in the corpus for analysis. All the collected data were qualitatively and quantitatively processed. In this paper, the metaphorical images in the songs were classified into three different kinds, namely structural metaphors, ontological metaphor, and orientational metaphors, of which the number of structural one ranks the first. The writer analyzed 46 structural metaphors to find out conceptual meaning transference from the vehicles to the tenors from cognitive perspectives and the rhetorical value distributed to songs from stylistic perspectives. Finally, the implication for learning, teaching and translating metaphor was presented.
\end{abstract}

Keywords: Metaphor, structural metaphor, love, songs, cognitive

\section{INTRODUCTION}

Metaphor in a language is like a flower of life. Life becomes more beautiful with the colorful flowers and language becomes more legend and meaningful with metaphorical images. Understanding metaphor is crucial to comprehend figurative language in literature and daily life. Metaphor is used to describe something that the author cannot adequately represent in a literal style. They can broaden or bring a fresh breath into a familiar or overused subject. Adding metaphors means adding interest and depth to writing. Metaphor creates more specific and clearer visual images of what the writer is trying to express. 
It is obvious that language is a tool for expressing human thought. It reflects the way people think and view the world around them. Each language has different characters but it is generally expressed through a simple meaning form of language: word. The meaning of any word is a matter of what we do with our language, not something hidden inside anyone's mind or brain so Hogan (2010) showed the close relation between word meaning and the semantic value. Language with a variety of sense is a thing that has changed all the time from the forms of words to the meaning in which people could remove, add, and transfer the meaning of words to be suitable with the context and intent of writers.

Using metaphor is a significant change in both cognition and linguistic style of language that enriches the content and makes writers' emotions sublimated. This semantic change in the use of metaphor makes an evolution of language in literature and communication. It can be said that metaphor is also a useful linguistic device for musicians to write impressive songs. Through love songs, metaphor is understood and studied more interestingly and effectively. Love is a beautiful song in life in which people often create unique words to give the beloved messengers to each other and with the power of metaphor; love becomes the wings in the sky. As a result, the occurrence of metaphors of love in songs increases the cognitive and linguistic value for the love that more easily touches the bottom of the heart of readers.

The stylistic definition of metaphor is approached as one stylistic device of a particular language variety that is relatively individual, such as the metaphors of politics, economy, and music. Each stylistic metaphorical image brings different values in each field. Seen from the cognitive approach, metaphor is a very powerful meaning transference tool as it reflects the way we conceptualize the world we live in. It is almost impossible to understand a thing without grouping it with other category members that share the same properties. In doing so, we acquire different kinds of concepts and, as a result, build our schemata of a genre. Metaphors supply these requirements. Often we treat them only as stylistic devices, but in fact, metaphorical expressions verbally represent the way of human thinking and reasoning. People tend to conceptualize emotions, love being one of them, metaphorically because both emotions and metaphors connected with them are inevitable parts of everyday life.

According to Lakoff and Johnson (1980), metaphor is a device of the poetic imagination and the rhetorical flourish - a matter of extraordinary language rather than ordinary language. As it is stated by Vo Dai Quang (2005), metaphor is word meaning transference based on the similarity between two things as regards function, character, size, shape, age, color, etc. Meanwhile Baars. B.J, 1998 defined metaphor as an application of a word or phrase to an 
object or concept, a comparison to that object or concept, not just literally denote. It is clear that the term metaphor refers to the meaning of the word that can be expanded beyond its literal meaning.

According to Lakoff and Johnson in Metaphors We Live By (1980) and Zoltan Kovecses in Metaphor: A Practical Introduction, there are 3 kinds of conceptual metaphors: structural metaphors, orientation metaphors, ontological metaphors.

a. Structural metaphors:

Structural metaphors are generally understood conceptual metaphors where one concept is metaphorically structured in terms of another. Structural metaphor is the most productive type of all conceptual metaphors.

b. Orientational metaphors:

Orientational metaphors organize immaterial concepts in terms of physical orientation: happiness is up (high spirits) and sadness is down (feeling low), the future is ahead and the past behind. The group of orientational metaphors is said to be connected with our orientation in space. (Lakoff, 1980:16).

c. Ontological metaphors:

In ontological metaphors, experiences are treated as concrete objects e.g. containers. When we deal with them in such a way we can "refer to them, categorize them, group them, and quantify them - and, by these means, reason about them" (Lakoff, 1980:25).

Conceptualist views consider metaphor as a cognitive mechanism used to structure our knowledge in the mind by means of one domain of experience understood in terms of the first one. A metaphor has two conceptual domains. One is the thing that is to be understood, which is called the target domain, and the other is the thing that is used to understand the first one, and it is called the source domain (Kövecses, 2002:4).

According to Barcelona (2000:3), Metaphor is the cognitive mechanism whereby one experiential domain is partially mapped or projected onto a different experiential domain so that the second domain is partially understood in terms of the first one. The tenor is the subject to which attributes are ascribed. The vehicle is the object whose attributes are borrowed. In the example "love is a game", "love" is compared to a game, describing it with the attributes of "game"; "love" is the tenor, and "a game" is the vehicle.

According to Jakobson (2003), metaphor has been pervasive in every field of life. This figurative language can be witnessed through its prevalence not only in art, music, sculpture, and literature but also in ordinary language. Metaphorical competence plays an essential part in boosting language ability and it is necessary to enhance the awareness about 
metaphor. There have been a great number of studies in which the writers expressed concern about metaphor. A holographic study of metaphors concerns love in Chinese" by Renying Yang (2008) makes a thorough analysis of love metaphors in Chinese basing on the conceptions of emotional metaphors by Lakoff, Kovecses and the others. This paper analyzed the conceptual metaphor of love in Chinese in relationship with characteristics and cultural identity. Here, perspectives of historical development and ideology were also introduced with a variety of metaphors of love originated from other languages. There are some outstanding works on the metaphor of love and metaphor of love in songs such as "The translation of Metaphor in English newspaper article" by Lam Thi Hong Dao (2012).

One more research mentioned in this paper is the one composed by Le Thuy Linh (2011). She took an interest in analyzing and comparing the metaphor of "love is fire" in English and Vietnamese. The metaphors are built based on the features of fire with different processes such as burning, maintaining and extinguish. The body heat is also compared with the heat of the fire. The work brings about the useful knowledge on metaphors and gives readers the interest in investigating metaphor of love in songs.

In short, these works play an important role in building language instructions in general and instructions for the use of metaphor in particular. However, these studies did not analyze the metaphors of love in songs deeply and systematically based on the cognitive and linguistic perspectives. Also, the number of metaphors of love quoted are not diverse and various. In addition, these have little authentic and practical value in teaching. It is the reason why a study entitled "metaphors of "love" in the English songs in the late 20th century from the cognitive and linguistic perspectives" with the hope of giving the readers interesting experience through the metaphoric images in songs as well as their artistic value and from this analysis to make a meaningful contribution to learning English in reading and writing skills for learners, teachers was made. This paper aimed to clarify the following questions:

1. What are the typical metaphorical images of love in English love songs in the late 20th century?

2. How are the metaphorical images of love cognitively expressed in the love songs?

3. What is the rhetorical value of the metaphorical images distributed to the songs?

\section{METHODS \\ Data}


The data for analysis are the samples randomly chosen from the English love songs of all kinds in the late 20th century. There are 68 songs used with 80 metaphorical verses of three types, of which 46 structural metaphorical images quoted in this paper to analyze. They are collected from websites, newspapers, magazines and books.

\section{Data Analysis Procedure}

The major methods which are used for this paper are qualitative and quantitative ones in which data was collected, categorized in three types and counted in the number of occurrence and the percentage of meaning items. The data was also analyzed qualitatively to find out the rhetorical value to the songs. It refers to the various procedures in the following.

First of all, official documents related to metaphor are collected. The task for the researcher is not to take such documents at face value. In addition to finding out the vital theoretical knowledge for the topic, the researcher must realize where the metaphorical images used are in songs, what terms they belong to, how they were constructed, and how they are used and interpreted. After analyzing and interpreting data generated from the examination of documents and records, the findings will be categorized and synthesized into meaning items.

\section{FINDINGS}

\section{Occurrence of Linguistic Items Used Metaphorically in Songs.}

Table 1.2: Occurrence of Conceptual metaphors denoting love in English songs in the late 20th century from the cognitive perspective

\begin{tabular}{llcl}
\hline Meaning items of metaphor & $\begin{array}{c}\text { Number of meaning items of } \\
\text { metaphor }\end{array}$ & $\begin{array}{c}\text { Percentage } \\
\text { (\%) }\end{array}$ \\
\hline 1 & Love is a concrete and real & 11 & 13.75 \\
& object & 4 & 5 \\
2 & Love is the abstract thing & 6 & 7.5 \\
3 & Love is light & 4 & 5 \\
4 & Love is madness & 2 & 2.5 \\
5 & Love is religion & 13 & 16.25 \\
6 & Love is closeness. & 5 & 6.25 \\
7 & Love is a living creature & 2 & 2.5 \\
8 & Love is magic & 5 & 6.25 \\
9 & Love is a natural phenomenon & 4 & 5 \\
10 & Love is music & 4 & 5 \\
11 & Love is a journey. & 5 & 6.25 \\
12 & Love is the heaven & 2 & 2.5 \\
13 & Love is a game. & 7 & 8.75 \\
14 & Love is fire & 4 & 5 \\
15 & Love is a war & 2 & 2.5 \\
16 & Love is deeper high & $\mathbf{8 0}$ & $\mathbf{1 0 0 \%}$ \\
& $\quad$ Total & & \\
\hline
\end{tabular}


A surprising result from the research is that there are 80 metaphorical images are quoted from 68 song lyrics and are distributed to 16 main meaning items of metaphor. "Metaphor of closeness" and "metaphor of concrete object" are used with the highest numbers $13(16.25 \%)$ and 10 (13.75\%) respectively.

The images used for these two types of metaphor are familiar to real life such as voice, shoulder, candle, holiday or mountain, etc. These things are the old images but bring the new emotions to human beings through metaphorical meaning transference. They wear new thinking on the basis of the old concept love. Meanwhile, the metaphors of religion, magic, music, game are less used at the same rate $(2.5 \%)$. This figure may not lead to any result or assessment because of the limited number of songs. The metaphor "love is fire" and "love is light" make up a comparative number $(8.75 \%$ and $7.5 \%)$ which shows quite a big favor for this type of metaphor. These images bring about positive thought and bright look about the passion of human beings.

\section{Occurrence of Love Metaphors in English Songs in Three Subtypes}

Table 2: The occurrence and percentage of conceptual metaphors denoting love in three subtypes.

\begin{tabular}{|c|c|c|c|c|}
\hline No & $\begin{array}{l}\text { Meaning items of } \\
\text { metaphor }\end{array}$ & $\begin{array}{c}\text { Ontological } \\
\text { metaphors (\%) }\end{array}$ & $\begin{array}{c}\text { Structural } \\
\text { metaphors (\%) }\end{array}$ & $\begin{array}{r}\text { Orientational } \\
\text { metaphors (\%) }\end{array}$ \\
\hline 1 & $\begin{array}{l}\text { Love is a concrete and } \\
\text { real object }\end{array}$ & 13.75 & & \\
\hline 2 & $\begin{array}{l}\text { Love is a living } \\
\text { creature }\end{array}$ & 6.25 & & \\
\hline 3 & $\begin{array}{l}\text { Love is a natural } \\
\text { phenomenon }\end{array}$ & 6.25 & & \\
\hline 4 & $\begin{array}{l}\text { Love is a game. } \\
\text { Total }\end{array}$ & $\begin{array}{l}2.5 \\
28.75\end{array}$ & & \\
\hline 5 & Love is religion & & 2.5 & \\
\hline 6 & Love is closeness. & & 16.25 & \\
\hline 7 & $\begin{array}{l}\text { Love is the abstract } \\
\text { thing }\end{array}$ & & 5 & \\
\hline 8 & Love is magic & & 2.5 & \\
\hline 9 & Love is madness & & 5 & \\
\hline 10 & Love is music & & 2.5 & \\
\hline 11 & Love is a journey. & & 5 & \\
\hline 12 & Love is the heaven & & 6.25 & \\
\hline 13 & Love is light & & 7.5 & \\
\hline 14 & Love is fire & & 8.75 & \\
\hline 15 & Love is a war & & 5 & \\
\hline & Total & \multicolumn{3}{|c|}{68.75} \\
\hline \multirow[t]{2}{*}{16} & Love is deeper high & & & 2.5 \\
\hline & Total & & & 2.5 \\
\hline
\end{tabular}


It is clear from the table that there is a significant difference in the number of conceptual metaphors of each type occurring in the songs. There are numerous structural metaphors found in the data and these are categorized under suitable conceptual metaphors. Noticeably, structural metaphors are found in songs with the highest occurrence, making up $68.75 \%$ of three subtypes. This group is the largest of the three and includes some of the most common samples. Ontological metaphors account for $28.75 \%$ and the lowest frequent type is orientational metaphors with $10 \%$. In short, there is a preference for using metaphor in structural type and it is hard to find out the orientational one in the songs collected.

\section{Analysis of Structural Metaphors and Their Rhetorical Value in Songs}

It can be said that the musicians make use of the effect of figurative language to support the content and rhetorical value of the songs. Metaphor can be thought of as a mechanism for empowering diction. It is thought of much as an instance of reaching a particular meaning that has the effect of arriving at a more immediate picture of reality. The power of metaphor is to create meanings by the simplest or most elaborate of comparisons between unlike elements. Metaphor has been acknowledged as a primary tool for writers. Thanks to them, every melody sublime to the deepest point of readers' heart.

It is a metaphor that is considered as a powerful device of language in order to make love sublime. Especially, love songs cannot run out of metaphorical imagines. Music without metaphor would be as a tree on a desert. It is not easy to have such romantic lyrics such as:

Love is a bird, she needs to fly

Let all the hurt inside of you die

You're frozen (Madonna-"Frozen")

Love and bird - a vivid comparison makes readers feel like flying with the free wings of love. Metaphor both describes and paints and lulls people into the sweet melody of songs. It is clear that metaphor can add an ornamental or poetic flourish to every word of songs.

It also gives new meanings to words already in common use in which love must be tight closeness between lovers. A new idea that love needs freedom is the opinion the writer wants to express. Metaphor in songs is much like its function within poetry and other written works: to relate two different things to each other to provide a deeper meaning or understanding of each. Many writers and lyricists use metaphor in songs to make personal experiences more universal and connect more strongly with a listener.

Metaphor in songs can also be used to create a stronger impression on topic. The use of metaphor in songs also makes the lyrics of the song more 
memorable for a listener, allowing him or her to find it later and listen to it again.

It can foster the cognitive function of conceptualizing-namely, generating or understanding concepts-by giving the concept a familiar such as "love is a journey", "love is a game", "love is music", etc. It is practical to allow readers to have a greater understanding of the concept, object, or character being described. This is done by comparing it to an item that may be more familiar to the reader.

I've been a miner for a heart of gold (the heart of gold)

Value of metaphor is purely artistic: to create an image that is beautiful or profound or otherwise produces the effect that the writer desires. For these reasons, writers have used the metaphor in literature since the earliest recorded stories. Many song writers and lyricists use metaphor in songs to make personal experiences more universal and connect more strongly with a listener.

What a feeling in my soul love burns brighter than sunshine

It's brighter than sunshine let the rain fall, I don't care

I'm yours and suddenly you're mine, suddenly you're mine

It's brighter than the sun (Aqualung - Brighter than Sunshine).

These sweet words come from the using metaphor in song. The experience becomes beautiful memories. The structural metaphorical images are really artistic and sophisticated.

\section{Love is Light}

A light in the dark shining your love into my life (Celine Dion - Because you love me)

Wherever lovers go, no matter how the weather is, love always brings them the sunshine. When lovers possess that light within, they will see it externally because it is the soul's light. So, keep that flame lit, and they will never feel the darkness. We all walk in the dark and each of us must learn to turn on our light with a warm heart. Love is light that dissolves all the walls between souls. Love is light that brightens every heart's darkness

Love is the soul's light, (The taste of morning- Rumi)

Cause we have the brightest love

Two lights that shine as one Morning glory and midnight sun

Ageless and ever evergreen... (Barbra Streisand- Evergreen)

Here is the rainbow I've been praying for.

It's gonna be a bright (bright), bright (bright) sunshiny day.

(Johnny Nash - I can see clearly now)

Love is light is one metaphor used in these sentences. Light is an indispensable thing for human beings, just as love is from lovers' point of view. Items such as "shine" and "brightest" are used to seek for light. They have indicated the essential role of love played in life, and his intention of searching for love. 
What a feeling in my soul love burns brighter than sunshine It's brighter than sunshine let the rain fall, I don't care (Aqualung - Brighter Than Sunshine) He's my laughter, my lover, my life He's my sunlight (Nina - Sunlight)

\section{Love is Madness}

Love is also a psychological illness which is stated as the insanity of human. Falling in love, people will experience the stages of emotions of which madness is considered a common symptom without right direction, decision and choice. Lover is described as absent-minded ones.

I'm crazy about her

She drives me out of my mind (Lakoff 1980: 49)

According to Young (2009: 148)), love can partially be viewed as "an emergent property of a cocktail of ancient neuropeptides and neurotransmitters". He shows that as a drug, the hormone enhances trust in humans and makes them more empathetic towards other people's emotions. Or as Young ends his essay: "after all, love is insanity". Many lexical items are used to express this type of emotion such as surreal, a fool, foolish beat or a riot. Minogue writes about love causing surreal or unreal feelings in 'Cowboy Style' and 'Harmony'.

The ordinary is surreal,

Peace and terror all in one. (Minogue -'Cowboy Style')

See me loving you

A fool without a lover (Diana Ross - Experience)

Just a foolish beat of my heart (Debbie Gibson - Foolish Beat)

In 'Drunk' the protagonist is experiencing psychosomatic symptoms caused by his desire for love.

I ache for the great experience

There's a riot in my senses (drunk' - Minogue)

The protagonist explains these symptoms by saying there's a riot in his senses; again, the grip on reality seems to disappear, resulting in the protagonist confusing the sensory perceptions. This desire for love is causing a shock in the protagonist; one sensory perception is causing other sensory channels to react as well and when there all of them are receiving stimuli, the result is complete sensory chaos, a literary riot of and in the protagonist's senses.

\section{Love is the Abstract Thing}

Love is an eternal topic, whether in daily life, in literary works, or in films, which are universal and complex. Due to certain cultural contexts or specific geography, love has its own uniqueness; even an individual has his or her own 
way of expressing love. While some people consider love as concrete things, the others hold love as elusive and abstract things. Hence, the conceptual metaphor theory has provided us an important method to explore the conceptual meaning of such emotional words as love.

There are many examples of metaphors of love as the abstract thing. They are common in everyday life as they present different aspects of this powerful emotion. The intensity plays an essential role in the way we think of love. The abstract thing can be elaborated to the items: inspiration, truth, dream, chance, happiness, loneliness, emptiness, etc.

You've been my inspiration

Through the lies, you were the truth

My world is a better place because of you (Celine Dion because you love me)

Loving and being loving is great happiness in life. The world will be better because of you because you are always my inspiration, my belief. Love is not always sweet and beautiful. For the broken- hearted people, love is a dark sky or lost way, broken dream and plan. His future seems to stop because love is over.

I thought I'd lost my way forever

Every dream and every plan

Every last chance slipped through my hand

And you smiled at me and it was over (Aaron Neville - I Owe You One)

A true Love is important in life. Someone who gives each other the unconditional love supports present and encourages future and their life will be full of happiness and sweet caress. Love means never having to say you're sorry. But in life not many people luckily have the forever true love:

Bye-bye happiness, hello loneliness

I think I'm-a gonna cry-y

Bye-bye love, bye bye sweet caress, hello emptiness

I feel like I could di-ie (Everly Brothers - Bye Bye Love)

Love is happiness, loneliness, sweet caress or emptiness depending on the lover' motion and the tones of passion and love.

And you complete the heart of me

Our love is all we need

Circle in the sand, circle in the sand (Belinda Carlisle - Circle in the Sand)

"Circle in the sand" is a concrete thing but it bears an abstract meaning that is a full love without any fracture. It is an expected image of all lovers.

\section{Love is Religion}

Love and religion are two topics intensively debated because there is no religion without love but to come to a happy ending in love, people must experience the strict rules of religion and to some extent, love is hindered by religion. As a result, there are beautiful love-religion stories but with the help 
from the God, the people who deserve to have a love, will have an expected love. If we put our heart in God's hand, he will place our heart in the hand of a worthy person. From the early day, love is considered as a religion. Kovecses (2002: 14.) gives the conceptual metaphor of the object of love is a deity. This conceptual metaphor is of particular interest as, according to Kovecses, it acts differently than most of its kind. Typically, he explains, conceptual metaphors use a source domain better understood and more concrete to define a more abstract and complex target domain. In 'Some Kind of Bliss', as the title of the song already indicates, the state of bliss is not without contradiction.

Succumb to this illusion

So strong, so deep (Minogue -Some Kind of Bliss)

This time the love may not have received blessing from above - and most probably not from the lovers' parents either - but it is sufficient for the lover. He feels happy and contented enough; there is no need to reach for the skies, sometimes it is simply better to enjoy what one has before her. Every day is all there is to show that the protagonist has his feet very firmly on the ground and he has taken a very mature stand on the situation

The Seraph lover in 'Looking for an Angel' can be included in this category.

With a peaceful smile,

You are from the temple

Won't you stay a while (Minogue 'Cowboy Style')

The same can be said of his love interest in 'Cowboy Style' - she is from the temple. This, in conjunction with the line with a peaceful smile, brings into mind Buddhism. The calming, peaceful presence of the writer's love interest encourages her to wish the love interest to stay for a while, thus possibly through guidance providing enlightenment. The surreal feelings the writer goes through later in the lyrics point out to this as well: the protagonist now finds and now feels and he feels as if his future life has just begun. Again, the different aspects of love merge: Eros is present, but so is stored and agape.

\section{Love is Closeness.}

The conceptual metaphor Love is closeness is used by Kovecses (2002, p. 64). Kovecses writes about statues portraying two people in love and the imagery used in depicting the love relationship: the two people can be bound together or inside each other - at the very least they are very close to each other. From this proximity of the subjects, Kovecses derives the conceptual metaphors of love is closeness.

\section{Being in love is being physically close.}

The distance between the two lovers is changed, which leads to the result that they fall in love, or that they want to fall in love.

Let me take you by the hand and lead you through the streets of London, I'll show you something to make you change your mind. 
(Beatles - The Streets of London)

But still, something between us holds together

Cos I've been holding you so damn tight (Ace Reject- sugabage)

In these two examples, the first person touches the second person by the hand and by the upper body respectively. This kind of physical closeness which can be called getting touched seems to be quite popular and preferred between lovers.

Anything, baby just let me get next to you

I only want to be by your side (Sade - By Your Side)

Get next to you and by your side are the expressions to show the closeness of the lovers which has the meaning that the first person is just near the second person and he can protect the second person from harm.

What's inside of my heart?

It ain't gonna change

So it shouldn't be so easy to walk away (Lionel Richie - I Call It Love)

This first-person wants to part with his beloved one at first. However, he finds that his heart does not change so he says it shouldn't be so easy to walk away. Though it seems that the first person is in a dilemma, the last sentence reveals his tendency to stay with the beloved one. Since it shouldn't be so easy to walk away then it is better to stay together with the beloved one

Problems arising from the relationship are the distance or the lost between lover.

No matter how near you'll be

You'll never belong to me (The Carpenters - I Can Dream Can't I)

Just can't live my life without you

Baby come here, have no fear (Elliott Yamin - Moody's Mood for Love)

Run to me baby and hold out your hand (P.Y.T. - Simply in Love with You")

On the surface, all the examples here mention that the second person is dynamic and is the one who needs to be loved. However, the real interpretation is as follows the first person is the one who is eager to be loved. But for some unknown reasons, the fir sty person does not wish to be the dynamic one. Therefore the first person asks the second person to be the dynamic one so that the first person can be in love

In these desperate times

We get pushed and shoved from every side (The Scorpions - Love Will Keep Us Alive)

This is a positive example. It looks like the two have no choice and are passive in getting together since they get pushed and shoved from every side. But no matter whether they are passive or reluctant to do anything, the truth is that they get together.

Though we go our separate way

Lookin' for better days (Neil Young - Separate Ways) 
This negative example is quite clear that both of the two go their separate ways and looking for better days. Then not a single one wants to keep this love. The reason is not that the days they stay together are bad, but they want to find better days

Finally, in 'Rhythm of Love', the protagonist states being together is good

So good together

Some people work better solo (Minogue- 'Rhythm of Love')

She does suggest that some people work better on their own: alone - or solo as Minogue writes. The protagonist is not like that; she could never be without the love interest. Being without the loved one would be not being at all.

\section{Love is Magic}

Magic is something supernatural, something that defies or even breaks the laws of nature, and cannot be explained by them. Magic is something outside of religion proper. The number of metaphoric expressions in the data required separating some elements, and treating magic and religion as separate source domains was a logical choice. Some examples of magic metaphor are mentioned in:

She cast her spell over me

She is bewitching (Lakoff 1980:49)

Although it is not important whether humans believe in magic or not, what is important is the fact that people are not indifferent to it. Magic affects people and fascinates them profoundly. Women especially are said to have the power to seduce men, hypnotize them or even, cast spells on them. As love is treated almost like a magical and inexplicable phenomenon, it is not difficult to understand why love is comprehended in terms of magic.

\section{Love is Music}

The conceptual metaphor Love is music is based on the conceptual metaphor Love is a collaborative work of art by Lakoff and Johnson. Lakoff and Johnson (1980) define the conceptual metaphor Love is a collaborative work of art to be “particularly forceful, insightful and appropriate" (pp. 140).

Everybody's saying' that music is love

Everybody's sayin' its love (Crosby Stills Nash - Music Is Love)

When words fail, music speaks. If love is music, lovers are the notes on the page and the melody in the heart. There is such a romantic music type and also there are some types of happy/ sad music so it is said that music is the voice of the heart. Love is like playing music: First, you must learn to play by the rules, and then you must forget the rules and play from the heart. Music often express the feeling and emotion of lovers and this is an effective way to connect the souls. 
In 'Rhythm of Love', Minogue plays with blending the domains and lexical fields of love dance and music.

You've got a good beat,

I can dance to you ...come on let's jam '(Minogue - Rhythm of Love')

The lover is more experienced, she wants to - and will - dance to the beat of her lover. The lovers are engaged in an intense dance to the beat of their hearts, the rhythm of their bodies. There is an evident connection between dance and love here. It is as if the protagonist is a virgin dreaming of her first love or first sexual experience. She wants to and is ready to enter the world of love but is afraid to take the first step, as she is not sure whether his feet will fail her. She wants to succumb to the budding love but is afraid he will get hurt or will not succeed. Or perhaps the writer has been hurt by love and is now having doubts whether she has the courage to give love another chance Just a Game)

Love is just a game, broken all the same (The Magic Numbers - Love Is

This quotation expresses a metaphor because love is not literally a game. By figuratively asserting that the Love is just a game, the writer uses the points of comparison between the love and a game to convey an understanding of the characteristic of love as a game.

\section{Love is Fire}

LOVE IS FIRE metaphor is an example of a structural metaphor.

"My heart is on fire, I do not want to get burned again, that kindled love in his heart."

Thanks to the metaphorical expression that kindled love in his heart, we can conceptualize love as having a beginning and an end just as fire has. When the fire is kindled, the love begins; when it goes out, the love ends.

"Her eyes were glistening jewels"

"Love is a rose"

In this example, the word rose has a connotative meaning that is thought to be the very beautiful and fresh object to people. So this meaning is transferred to refer to the characteristic of love to imply that love is lovely and wonderful like a flower. The similarity in this case between a love and a natural thing is about the characteristic. This is one of the metaphorical imaginations of love. So metaphor in this definition is understood as a conceptual projection whereby one experiential domain is understood in terms of another. In the above example, the essence of love is likened and understood in terms of a characteristic of a rose.

\section{CONCLUSION AND SUGGESTION Conclusion}


The researcher clarifies the metaphorical images of love in songs, analyzes and categorizes 80 metaphorical images into 3 subtypes: ontological, structural or orientational metaphors with 16 sets of meaning. Then, the writer introduces and analyzes how structural metaphors are used and the rhetorical value in these songs. Lastly, some discussions are given about the percentage of the occurrence of metaphors in songs. We cannot refuse the role of metaphors in shaping our colorful pictures on love.

Many examples of metaphors of love which I try to present in the paper are common in everyday life as they present different aspects of this powerful emotion. Without the notion of metaphor, we would not be able to comprehend such an abstract feeling as love. The intensity plays an essential role in the way we think of love, for instance. The conceptual metaphor - love is fire emphasizes the existence of love (on fire), it is intensity (flames), duration and shows how love affects people (He was consumed by love). Due to the existence of metaphor, the most powerful emotions, love being one of them, can be interpreted gently.

\section{Suggestion}

Most important, being aware of metaphors reminds us of the central role that poetic skills play in our thought. Finding a metaphor plays a vital role in feeling and perceiving the value of literature. After studying metaphors of love in English love songs, I have found out implications for using metaphors in general and metaphors of love in particular for learners, teachers, and translators.

\section{Suggestion for Learners}

Once learners are able to have their own metaphors and use them to promote the ideas flexibly, they will become metaphor masters. If the learners know to take advantages of the benefit of using metaphor, they can improve all the skills in learning a second language.

Conceptual metaphor provides students with the possibility of understanding one concept in terms of another. From a domain, they can refer to many various domains by the metaphorical expressions. As a result, they will broaden their vocabulary and make them more productive.

Learners should know what a metaphor is if they are studying examples of metaphors in text. Simply knowing the definition, however, is not sufficient. They should be able to identify examples of metaphors in the text on their own. They should be able to explain the purpose of the metaphor and analyze how it contributes to the theme of the work. Thus, applying conceptual metaphors in learning language will help students improve their reading comprehension a lot. 
When studying one language, it is necessary not only to study vocabulary, grammar, reading, writing, speaking or listening, but also to know how to use language in a natural way. Metaphor is specially used in daily life, in any languages, and in many situations. In both spoken language and literature language, metaphor can frequently appear. As soon as understanding the message of each metaphor in songs and literal works, learners can easily communicate with native speakers naturally or use metaphor flexibly in their own writing. So, metaphor plays an important role in improving reading and writing skills. It is necessary to write paragraphs containing a metaphor appropriately as possible. Learners should use metaphors in their own writing to train their language competence better. As students become aware of their own metaphors for learning they can recognize how their language competence progresses.

In addition to the above skills, learning literature cannot lack using metaphor. The use of metaphor in poetry is one of the most important aspects of poetic style that must be mastered. Despite being the major students of English, they have few chances to practice using metaphor in writing. They still get a loss to understand and analyze metaphor in song or literal works. Therefore, when learning English literature, they must try their best to identify, analyze and use metaphor steps by steps from sentence to text.

\section{Suggestion for Teachers}

Not many students understand metaphor clearly and dare use metaphor in communication as well as in literal works frequently. Some can use metaphor in their writing but illogically and inflexibly. Hence, teachers must spend enough time and create appropriate methods to teach them to learn it in the best way.

Teachers should make their students aware of the applicability and significance of metaphors. The students should understand the nature conceptual metaphor and how it can be applied in daily life. Teachers can create interesting lessons to inspire learners to be absorbed in metaphor with the easy and exciting activities such as sharing examples, brainstorming, trying composing short poems...

Metaphor is an effective language tool for teachers to teach vocabulary in the collocation of word. Metaphor is frequently used in poetry, as poets endeavor to find creative ways to express experience. Encouraging students to use metaphors will help them improve their writing ability and produce interesting pieces that others will enjoy reading. It can be difficult for students to create their own metaphors. However, there are activities that teachers can use to help students understand metaphors and to inspire the use of these literary devices to help bring writing to life 
Students often limit their descriptive writing to what they see. Teachers make students think about all five senses when they are writing. For example: Write a short poem about "love". (Teachers can suggest making a list of love metaphors., "Love is a..." and fill in the end with the first thing students think of that feels true: love is a race, love is chocolate, love is a fight, dream,...Then Students can start to describe what they know and think about).

The influence of the first language in metaphoric processing has been explained as the result of the cultural background and expectations of that language, which affects the way learners, conceptualize the target language and process metaphors in the target language (Boers, 2003; Kövecses, 2004). Thus, it is important that learners discern the way figurative language is used in a particular culture because learning a language means learning about culture learners can gain linguistic and non-linguistic knowledge. As a means of cultural transmission, metaphors can raise learners' awareness of the relationship. Consequently, teachers should provide students with knowledge of a culture.

In short, the data consists of 80 verses from 68 song lyrics and even though the number of lyrics did not seem excessive in the beginning, the workload needed in finding and analyzing all the metaphorical expressions in the 80 data proved out to be staggering. The number of song lyrics should have been reduced in order not to deviate from the typical extent of theses. Organizing metaphorical expressions under the appropriate conceptual metaphors works well but I am not contented with the way each of them is analyzed. With the love for literature, I could have analyzed every example elaborately and interestingly but because of limitation of pages and time, I only mentioned them generally.

This research mainly focuses on the semantic mechanism of metaphors used in English love songs by famous bands and writers. Thus, there are still some exciting aspects that need further studies: It would be a fascinating idea to widen the topic to other fields such as metaphors in folk songs, in poetry, novels... It would be better to analyze metaphor from other perspectives, also, analyzing and clarifying the implications for teacher to enhance metaphor competence for student should be paid attention. Furthermore, the later one could choose only one metaphor to deepen such as "love is religion" with many sources of material. 


\section{REFERENCES}

Baars, B. J. (1998), Metaphors of consciousness TINS Vol. 21, No. 2.

Barcelona (2000:3), Introduction. The cognitive theory of metaphor and metonymy, Berlin and New York: Moutoii de Gruyter.

Cơ, T. V. (2011), Nhũng khái niệm Ngôn ngữ học tri nhận liên quan đến Văn hoá hoc (p4), Culture and information press

Dao , L. T. H. (2012), The translation of Metaphor in English newspaper article, Da Nang University

Jakobson (2003), Two aspects of language and two types of Aphasic. Fundamentals of language. $2^{\text {nd }}$ ed., rev. The Hague: Mouton,

Lakoff, George (1993), The contemporary theory of metaphor. In A. Ortony (Ed.) Metaphor and Thought. (pp. 202-251) Cambridge: Cambridge University Press

Lakoff, George, Johnson M. (1980), Metaphors We Live By.University of Chicago Press.

Lakoff, George, Turner, Mark (1989), More Than Cool Reason: A field Guide To Poetic Metaphor. University of Chicago Press. Merwin, W. S 1973

Linh, L. T. T (2011), metaphor of "love is fire" in English and Vietnamese, HCM education university

Patrick Hogan (2010), The-Cambridge-Encyclopedia-Language-Sciences: Word meaning, University of Brighton

Quang, V.Đ (2005), Semantics (ngũ nghĩa hoc), Culture and information press.

Yang. A. (2008) Holographic Study of Metaphors Concerning Love in Chinese. Renying Yang, North China University 